\title{
Competition Between Fusarium pseudograminearum and Cochliobolus sativus Observed in Field and Greenhouse Studies
}

\author{
Erin E. Gunnink Troth, Jeffrey A. Johnston, and Alan T. Dyer ${ }^{\dagger}$
}

Department of Plant Sciences and Plant Pathology, Montana State University, Bozeman 59717-3150.

Accepted for publication 24 September 2017.

ABSTRACT

\begin{abstract}
Among root pathogens, one of the most documented antagonisms is the suppression of Cochliobolus sativus by Fusarium (roseum) species. Unfortunately, previous studies involved single isolates of each pathogen and thus, provided no indication of the spectrum of responses that occur across the respective species. To investigate the variability in interactions between Cochliobolus sativus and Fusarium pseudograminearum, field and greenhouse trials were conducted that included monitoring of spring wheat plant health and monitoring of pathogen populations via quantitative real-time polymerase chain reaction. The interactions between two isolates of $C$. sativus and four isolates of $F$. pseudograminearum were explored in three geographically distinct wheat fields. To complement field trials and to limit potentially confounding environmental variables that are often associated with field studies, greenhouse trials were performed that investigated the interactions among and between three isolates of $C$. sativus and four isolates of $F$. pseudograminearum. Across field locations, C. sativus isolate Cs 2344 consistently and significantly reduced Fusarium
\end{abstract}

populations by an average of $20.1 \%$. Similarly, $F$. pseudograminearum isolate Fp2228 consistently and significantly reduced $C$. sativus field populations by an average of $30.9 \%$. No interaction was detected in the field between pathogen species with regards to disease or crop losses. Greenhouse results confirmed a powerful (>99\%), broadly effective suppression of Fusarium populations by isolate Cs2344. Among greenhouse trials, additional isolate-isolate interactions were observed affecting Fusarium populations. Due to lower C. sativus population sizes in greenhouse trials, significant Fusarium suppression of $C$. sativus was only detected in one isolate-isolate interaction. This study is the first to demonstrate suppression of Fusarium spp. by C. sativus in field and greenhouse settings. These findings also reveal a complex competitive interaction between these two pathogen species that was previously unknown.

Additional keywords: Common root rot, Fusarium crown rot, population dynamics.
Fusarium crown rot (FCR) and common root rot (CRR) negatively affect small grain production worldwide (Cassini 1981; Fernandez and Jefferson 2004; Smiley et al. 2005; Wildermuth et al. 1997). FCR is caused by a complex of Fusarium spp. that includes Fusarium pseudograminearum (O’Donnell \& T. Aoki) (group I) (= Gibberella coronicola), F. graminearum Schwabe (group II) (= G. zeae (Schwein.) Petch), F. culmorum (Wm. G. Sm.) Sacc., F. avenaceum (Fr.) Sacc., F. acuminatum Ellis \& Everh., F. equiseti (Corda) Sacc., F. crookwellense, and Microdochium nivale (Fr.) Samuels \& I. C. Hallett (=F. nivale) (Cook 1981; Smiley and Patterson 1996; Wiese 1987). Among these, the most important root pathogens are F. pseudograminearum and F. culmorum (Cook 2010; MoyaElizondo et al. 2011b; Smiley and Patterson 1996). Summer temperatures drive the relative distribution of these two species, with F. culmorum preferring cooler temperatures (Cook 2010; Dyer et al. 2009; Moya-Elizondo et al. 2011b; Smiley and Patterson 1996) and $F$. pseudograminearum thriving at warmer temperatures (Cook 2010; Moya-Elizondo et al. 2011b). Fusarium spp. have a broad distribution; a recent Montana survey detected F. culmorum and F. pseudograminearum in $57 \%$ of spring and winter wheat fields sampled (Moya-Elizondo et al. 2011b). Numerous studies of losses due to FCR have been conducted, with losses ranging from 25 to $46 \%$ (Burgess et al. 1981; Dodman and Wildermuth 1987; Moya-Elizondo et al. 2011b).

In contrast to FCR, CRR is caused solely by Cochliobolus sativus (S. Ito \& Kurib.) Drechsler ex Dastur (= Bipolaris sorokiniana Shoemaker) (Mathre et al. 2003). Incidence of $C$. sativus varies substantially across its range, with incidences as low as $3 \%$ in the

${ }^{\dagger}$ Corresponding author: A. T. Dyer; E-mail: adyer@montana.edu

(c) 2018 The American Phytopathological Society
Pacific Northwest (Smiley and Patterson 1996) to greater than $93 \%$ in Montana (Moya-Elizondo et al. 2011b). Losses due to CRR range from $3 \%$ to as high as $31 \%$ for dryland fields (Ledingham et al. 1973; Moya-Elizondo et al. 2011b; Smiley et al. 2005).

Agriculture in semiarid conditions particularly benefits from no-till production systems due to greater soil water recharge and decreased evaporative losses. This has driven no-till adoption throughout many wheat-growing areas of the world (Cline 2007). Unfortunately, no-till agriculture is also linked to dramatic changes in root and crown diseases. These changes are associated with changes in environment, plant residue levels, and shifts in the microflora that occur within these production systems (Bockus and Shroyer 1998; Weller et al. 1986). With regards to FCR, no-till adoption has resulted in increases in disease severity (Burgess et al. 2001; Wildermuth et al. 1997; Windels and Wiersma 1992). The increase in disease severity is likely due to an overall increase in survival of Fusarium spp. (Pereyra et al. 2004), as well as shifts in species composition that have shown an increase in prevalence of the residue-dependent pathogen F. pseudograminearum, with a corresponding decrease in frequency of the more soilborne F. culmorum (Dyer et al. 2009; Scherm et al. 2013). In contrast to FCR, CRR has been declining under no-till production (Conner et al. 1987; Tinline and Spurr 1991; Windels and Wiersma 1992). The mechanisms behind this development are unknown, because overwinter survival of C. sativus was predicted to be enhanced by the increased persistence of plant residues in no-till systems (Wildermuth et al. 1997). It has been speculated that $C$. sativus is being suppressed by changes in the microflora that occur due to the adoption of no-till production practices (Tinline and Spurr 1991). It is worth noting that a concurrent increase in Fusarium spp. and decrease in C. sativus has been observed with the adoption of no-till practices (Windels and Wiersma 1992).

Reports of antagonisms among plant pathogens are relatively sparse (Bruehl 1987). The paucity of reports may belie their common occurrence. A recent meta-analysis suggests that these interactions 
are probably much more prevalent than previously appreciated (Stephens et al. 2013). Reported pathogen-on-pathogen antagonisms encompass a diverse cross section of plant disease systems, including tree pathogens and wood rotting fungi (Boddy 2000; Gibbs and Smith 1978), storage rotting fungi (El Hadrami et al. 2007; Yang et al. 2008), foliar pathogens (Le May et al. 2009; Nolan et al. 1999), and root rots (Ledingham 1942; Moya-Elizondo et al. 2011a; Scardaci and Webster 1981). Studies of foliar pathogens appear most common, with antagonisms reported among foliar pathogens of wheat, barley, and pea (da Luz and Bergstrom 1987; Le May et al. 2009; Nolan et al. 1999; Round and Wheeler 1978). This is likely due to their relative ease of observation and not due to some innate association.

Among root pathogens, one of the most documented antagonisms is between Fusarium spp. and C. sativus (Fernandez and Jefferson 2004; Moya-Elizondo et al. 2011a; Scardaci and Webster 1981; Tinline 1977). In field surveys, populations of $C$. sativus negatively correlate with those of Fusarium spp. (Fernandez and Jefferson 2004; Moya-Elizondo et al. 2011a). Likewise, in regions heavily affected by FCR, CRR has been reported as rare (Smiley and Patterson 1996). Other studies suggest that the overall impact of Fusarium-Cochliobolus interactions on crop production systems may be positive (Scardaci and Webster 1981). In controlled studies of these interactions, Fusarium spp. are implicated in the suppression of $C$. sativus, with no reciprocal suppression by $C$. sativus being demonstrated (Fernandez and Jefferson 2004; Moya-Elizondo et al. 2011a; Scardaci and Webster 1981). Unfortunately, these studies involve single isolates of each pathogen and provide no indication of the spectrum of responses that occur across the respective species. A series of trials was conducted in field and greenhouse settings to explore whether significant variability occurred among individuals of both species to suppress and be suppressed, the results of which are reported here. These findings may have significant implications as to the role and scope antagonisms play in the ecology of these two pathogen species, and may illuminate the consequences of common disease management measures on crop production systems.

\section{MATERIALS AND METHODS}

Isolate selection. Field and greenhouse trials were conducted to explore the interactions between $F$. pseudograminearum and $C$. sativus. All F. pseudograminearum and $C$. sativus isolates were collected from Montana wheat and barley fields. Four isolates of $F$. pseudograminearum were used in both the field and greenhouse trials. Two isolates of $C$. sativus (Cs2016 and Cs2344) were used in the field trials, with a third isolate (Cs1033) added for the greenhouse trials (Table 1). Among the isolates used, isolates Fp2228 and Cs2344 were selected due to their use in an initial study that explored the dynamics between $F$. pseudograminearum and $C$. sativus (Moya-Elizondo et al. 2011a). The three other $F$. pseudograminearum isolates were chosen because they were pathogenic on wheat, and varied in their deoxynivalenol (DON) production (Table 1); DON is a proven inhibitor of protein biosynthesis of other fungi (Lutz et al. 2003). The two additional $C$. sativus isolates were chosen because of their known pathogenicity on wheat.

Field trials. In May 2014, three trials were planted to evaluate the interactions between populations for several isolates of $F$. pseudograminearum and $C$. sativus as quantified at senescence. The trials were conducted at three locations near Bozeman, MT (Table 2), all of which were tilled in fall 2013. The experimental unit was a four-row plot, $3 \mathrm{~m}$ long with $30 \mathrm{~cm}$ centers. Rows were seeded with cultivar McNeal (Montana Agricultural Experiment Station, Montana State University, 1995) approximately $2.5 \mathrm{~cm}$ deep at a rate of 150 seeds per 3-m row using a Marvin Berg plot cone seeder. Weeds were controlled at all locations by hand hoeing and through the application of broadleaf herbicides as necessary (Table 3 ).

TABLE 1. Cochliobolus sativus and Fusarium pseudograminearum isolates used in field (F) and greenhouse (G) trials, including information on their source and deoxynivalenol (DON) production

\begin{tabular}{|c|c|c|c|c|c|c|}
\hline Isolate & Species & Year & Location & County & $\mathrm{DON}^{\mathrm{a}}$ & Trial use \\
\hline Fp2228 & F. pseudograminearum & 2002 & Loma & Liberty & $0.55 \mathrm{ppm}$ & $\mathrm{F}, \mathrm{G}$ \\
\hline Fp2234 & F. pseudograminearum & 2002 & Loma & Liberty & Not detected & $\mathrm{F}, \mathrm{G}$ \\
\hline Fp2278 & F. pseudograminearum & 2003 & Conrad & Pondera & $65.6 \mathrm{ppm}$ & $\mathrm{F}, \mathrm{G}$ \\
\hline Cs1033 & C. sativus & 1994 & $\ldots$ & Glacier & $\mathrm{n} / \mathrm{a}$ & $\mathrm{G}$ \\
\hline Cs2016 & C. sativus & 1997 & Moccasin & Judith Basin & $\mathrm{n} / \mathrm{a}$ & $\mathrm{F}, \mathrm{G}$ \\
\hline Cs2344 & C. sativus & 2007 & Carter & Choteau & $\mathrm{n} / \mathrm{a}$ & $\mathrm{F}, \mathrm{G}$ \\
\hline
\end{tabular}

a Abbreviation: $\mathrm{n} / \mathrm{a}=$ not applicable.

TABLE 2. Conditions at each field location, including soil type, annual precipitation (precip), soil fertility levels, and average historical temperatures (temp) from May through August ${ }^{\mathrm{a}}$

\begin{tabular}{llcccccc}
\hline Location name & \multicolumn{1}{c}{ Soil type } & $\begin{array}{c}\text { Slope } \\
(\%)\end{array}$ & $\begin{array}{c}\text { Average precip } \\
(\mathrm{cm})\end{array}$ & $\begin{array}{c}\text { Average high temp } \\
\left({ }^{\circ} \mathrm{C}\right)\end{array}$ & $\begin{array}{c}\text { Average low temp } \\
\left({ }^{\circ} \mathrm{C}\right)\end{array}$ & $\begin{array}{c}\text { Previous field } \\
\text { season }\end{array}$ & $\begin{array}{c}\text { NPK levels } \\
(\mathrm{ppm})\end{array}$ \\
\hline $\begin{array}{l}\text { Arthur H. Post Research } \\
\quad \text { Farm }\end{array}$ & $\begin{array}{l}\text { Amsterdam-Quagle silt } \\
\text { loam }\end{array}$ & 4 to 8 & 44 & 23.7 & 8.4 & Fallow & $363-22-451$ \\
Fort Ellis Research Farm & $\begin{array}{l}\text { Blackmore silt loam } \\
\text { Lutz Research Farm }\end{array}$ & $\begin{array}{c}4 \text { to } 8 \\
\text { Blackdog silt loam }\end{array}$ & 5 to 4 & 46 & 23.3 & 8.3 & $\begin{array}{c}\text { Spring wheat } \\
\text { Winter wheat }\end{array}$ \\
\hline
\end{tabular}

a Soil type and slopes were sourced from SoilWeb (University of California Davis, United States Department of Agriculture Natural Resources Conservation Service, and University of California).

TABLE 3. A 2014 calendar of field activity at each location including planting, collection of response data, harvest, and herbicide applications and rates ${ }^{\text {a }}$

\begin{tabular}{|c|c|c|c|c|c|c|c|}
\hline Location name & Planting & Emergence & Vigor & Tiller counts & Harvest & Herbicide application & Application rate \\
\hline Arthur H. Post Research Farm & 14 May & 27 May & 23 June & 6 August & 29 August & 2 June & 1.1 liters/ha ( $15 \mathrm{oz} / \mathrm{acre})$ \\
\hline Fort Ellis Research Farm & 15 May & 27 May & 23 June & 6 August & 26 August & None & None \\
\hline Lutz Research Farm & 21 May & 30 May & 23 June & 15 August & 27 August & 4 June & 2.3 liters/ha (32 oz/acre) \\
\hline
\end{tabular}

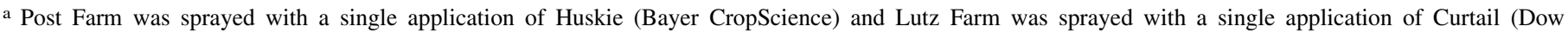
AgroSciences). 
Plots were inoculated in-furrow at planting with $18 \mathrm{~g}$ of fungalinfested oat kernel inoculum per 3-m row (Mathre and Johnston 1975). In plots that were inoculated with both $C$. sativus and F. pseudograminearum, $36 \mathrm{~g}$ of oat kernel inoculum was planted with the wheat seed, and no oat kernel inoculum was planted in the uninoculated control plots. Each trial followed a basic three-by-five design (two isolates of $C$. sativus plus a negative control by four isolates of $F$. pseudograminearum plus a negative control), for a total of 15 treatments. The treatments were planted in randomized complete blocks with four replicates at each location, for a total of 60 plots per field location.

Plant emergence was recorded between single- and two-leaf growth stages (Feeke's growth stage 1) at 9 to 13 days after planting. Emergence was recorded for the rightmost center row (row 3 in the plot) (Table 3). When row canopies had begun to close due to leaf overlap (during the tillering stage of development and before Feeke's stem extension stages had begun), vigor ratings were recorded. Vigor ratings reflect overall midseason plant health and take into account plant height, fullness of the rows, and stand. Vigor ratings were assigned on a scale of 0 to 5 , with 0 being assigned to plots with no plants and 5 to plots that exhibit row complete closure with no gaps or stunting. Tiller counts were taken for $1 \mathrm{~m}$ of an internal row for each plot when locations were at the end of flowering and at the beginning of ripening. Aborted tillers were not counted because they were empty of seed.

For yield, the middle two rows of each plot were harvested with a single-row Suzue rice binder (Mitsubishi Agricultural Machinery Co., Ltd., Tokyo) and threshed using a Vogel thresher (Bill's Welding, Pullman, WA). One week after harvest, stem and crown samples were taken from all field locations following established protocols (Hogg et al. 2007). This sampling process involved collecting crowns and stems from $15 \mathrm{~cm}$ of row from five randomly selected locations in the middle two rows of each plot. This provided more than 100 stem and crown samples per plot. The samples were cleaned of soil, leaf sheaths, and leaf matter to expose the culms and crowns that were then evaluated for visual disease symptoms.

Crowns were scored for disease severity after harvest, with all being scored within 1 month of harvest. Individual tillers were scored on a scale of 1 to 4 , such that $1=0$ to $25,2=25$ to $50,3=50$ to 75 , and $4=75$ to $100 \%$ discoloration, which may extend above the first node to the second or third nodes. The scores were then weighted using a standard method to achieve an overall disease severity score for each plot (Dodman and Wildermuth 1987; Wildermuth et al. 2001). Disease severity score was calculated by summing the number of tillers in each severity category and multiplying by the value of the category, then dividing by the total number of tillers scored. Significant correlations between disease severity score and both Fusarium populations and yield have been reported (Hogg et al. 2007; Knight and Sutherland 2015).

Greenhouse trials. During fall and winter 2014, three trials were conducted in the greenhouse to complement the field trials in evaluating $F$. pseudograminearum and $C$. sativus population dynamics. As in the field, the spring wheat McNeal was used as the host, and the same fungal isolates were used, with the sole addition of $C$. sativus isolate 1033. Experiments were planted on 11 August, 8 September, and 25 November 2014. Trials continued until plant senescence, which occurred at 107 days for trial 1, 95 days for trial 2 , and 78 days for trial 3.

Pots were 10 by 10 by $10 \mathrm{~cm}$ and held $400 \mathrm{~g}$ of pasteurized greenhouse soil mix at $1 / 3$ sand, $1 / 3$ peat, and $1 / 3$ topsoil with a wetting agent (Aquagrow 2000; Aquatrols, Cherry Hill, NJ) $(\mathrm{pH}=$ 6.2 to 6.8 ). Each trial followed a four-by-five experimental design (three isolates of $C$. sativus and a negative control by four isolates of F. pseudograminearum and a negative control), for a total of 20 treatments with four replicates, resulting in 80 pots per trial in a randomized complete block design. Pots were inoculated with $0.5 \mathrm{~g}$ of pathogen-infested oat kernel inoculum per pathogen at planting, and subsequently inoculated with spore inoculum 14 days after planting to ensure sufficient disease pressure (Mudge et al. 2006). $\mathrm{McNeal}$ wheat seed used for these trials was surface sterilized with $10 \%$ bleach for $60 \mathrm{~s}$, rinsed with distilled water, and left to dry overnight prior to planting. Four seeds and oat inoculum (Mathre and Johnston 1975) were placed $4.5 \mathrm{~cm}$ deep in the pot and covered with $4.5 \mathrm{~cm}$ of autoclaved greenhouse soil mix to reduce the potential spread of spores. Seed were placed $1 \mathrm{~cm}$ diagonally from each corner of the pot. Each pot was later inoculated with $5 \mathrm{ml}$ of each spore suspension as appropriate to its treatment, at a density of 2.0 to $2.6 \times 10^{4}$ spores $/ \mathrm{ml}$ (C. sativus conidia or $F$. pseudograminearum macroconidia), based on hemocytometer counts, and dispensed using a P1000 Pipetman; nothing was pipetted onto the uninoculated controls. Photoperiod was extended to $16 \mathrm{~h}$ using GE Multi-Vapor MVR1000/C/U lighting (General Electric Company, Cleveland, $\mathrm{OH}$ ), with a daytime temperature of $25^{\circ} \mathrm{C}$ and a nighttime temperature of $23^{\circ} \mathrm{C}$. Once plants headed (Feeke's growth stage 10.1), all surviving plants were harvested from pots by hand. All stems from a single pot were cleaned, bundled, and dried in preparation for DNA extraction. Yield data were not collected because the pot size restricts reliable seed production.

DNA isolation and sampling. To isolate DNA of Fusarium spp. and $C$. sativus from within wheat crown tissue collected from field trials, leaf sheath tissue was removed from the crown and stem samples. Thirty stems were then randomly selected from each field plot sample. Single 3-mm stem sections were cut from the first internode above the crown for each of the selected stems using rotary fabric cutters modified to hold two blades to ensure the excision of 3-mm-long stem segments. DNA was extracted from the resulting stem samples using FastDNA kits (Hogg et al. 2007) (QBiogene Inc., Irvine, CA). In this protocol, samples sit on ice for $30 \mathrm{~min}$ in an extraction buffer consisting of $800 \mu \mathrm{l}$ of CLS-VF buffer, $200 \mu \mathrm{l}$ of phenol-chloroform-isoamyl alcohol (25:24:1, $\mathrm{pH}$ 8.0 ), and $25 \mathrm{mg}$ of polyvinylpyrrolidone. Samples are then homogenized in a FastPrep FP120 (QBiogene Inc.) for $45 \mathrm{~s}$ at a speed of $6.0 \mathrm{~m} / \mathrm{s}$ and centrifuged. The supernatant is then bound to binding matrix and again centrifuged, with the liquid subsequently decanted. The resulting matrix-bound DNA is then vacuum dried in a SpeedVac SVC100 (Savant, Farmingdale, NY) to remove residual ethanol, and DNA is eluted from the matrix in $100 \mu \mathrm{l}$ of moleculargrade water.

DNA extractions of greenhouse samples followed the same protocol, with the exception that equal numbers of stem sections were taken from each plant in a pot to total 28 stem sections. This was necessary because there were four or fewer plants per pot.

Quantification of pathogen populations. Quantitative polymerase chain reaction (qPCR) copy numbers were calculated based on standard curves and were used as a proxy for $F$. pseudograminearum and $C$. sativus population sizes. The $\mathrm{qPCR}$ analyses were performed following protocols detailed by Hogg et al. (2007) for Fusarium spp. and Moya-Elizondo et al. (2011b) for C. sativus populations. These procedures have been used successfully in the past to monitor populations of these pathogens and have correlated with disease severity and crop yield losses (Hogg et al. 2007, 2010; Moya-Elizondo et al. 2011a,b). The primer-probe combination used to quantify $F$. pseudograminearum is based on the trichodiene synthase (tri5) gene (Hogg et al. 2007). For C. sativus, the primer-probe combination is based on the glyceraldehyde-3phosphate dehydrogenase $(g p d)$ gene, which has been described previously (Moya-Elizondo et al. 2011a).

All qPCR assays were conducted using the CFX Connect RealTime PCR system (Bio-Rad Laboratories, Hercules, CA) and a twostep protocol with the following thermocycling parameters: $55^{\circ} \mathrm{C}$ for $2 \mathrm{~min}, 95^{\circ} \mathrm{C}$ for $10 \mathrm{~min}$, and 40 cycles of $94^{\circ} \mathrm{C}$ for $15 \mathrm{~s}$ and $62^{\circ} \mathrm{C}$ for $60 \mathrm{~s}$. The $25-\mu \mathrm{l}$ qPCR contained $12.5 \mu \mathrm{l}$ of Universal TaqMan Master Mix (Applied Biosystems, Carlsbad, CA), $2.5 \mu \mathrm{l}$ of $2 \mu \mathrm{M}$ TaqMan probe, $2.25 \mu \mathrm{l}$ of a 1:1 mixture of $20 \mu \mathrm{M}$ forward and 
reverse primers (Integrated DNA Technologies, Inc. Coralville, IA), $2.75 \mu \mathrm{l}$ of molecular-grade water, and $5 \mu \mathrm{l}$ of DNA sample. Samples were standardized by tissue quantity, which was found to be superior to total DNA (Knight et al. 2012). Each plate included positive controls consisting of mycelial DNA extracted from either F. pseudograminearum or C. sativus grown on potato dextrose agar and V8 agar, respectively. Each run also included three replicates of five DNA standards consisting of a dilution series ranging from $10^{2}$ to $10^{6}$ copies of each target gene. Standard curves were produced by plotting the log of concentration of the DNA standards versus the cycle threshold $(\mathrm{Cq})$ values; these displayed strong relationships, with $R^{2}$ values always exceeding 0.98 . For $F$. pseudograminearum, the DNA standards were derived from a cloned fragment of the tri5 gene taken from F. culmorum isolate 2223 (Hogg et al. 2007). For C. sativus, the standards were cloned fragments of the gpd gene from C. sativus 2344 (Moya-Elizondo et al. 2011a). All DNA samples were quantified by qPCR three times as technical replicates. For quality control among technical replicates, the standard deviation between Cq values of the three technical replicates, or the number of cycles it took for a sample to amplify above the detection threshold of fluorescence, was examined to ensure that standard deviation did not exceed 0.5 cycles; excessive variation in $\mathrm{Cq}$ values was not observed. DNA samples were not augmented with internal controls to test for inhibition because prior work has found no evidence of inhibition of qPCR using DNA extracted in the method detailed previously (Hogg et al. 2010; Moya-Elizondo et al. 2011a,b). For analysis purposes, DNA copy numbers of the gpd and tri5 genes were interpreted as the quantified crown population of $C$. sativus and the $F$. roseum group ( $F$. culmorum, $F$. graminearum, and $F$. pseudograminearum), respectively.

Statistical analyses. Analyses of field trials were conducted using linear models which included location (Post Farm, Fort Ellis, and Lutz Farm), F. pseudograminearum isolate, C. sativus isolate, and interactions between these three factors with regard to emergence, vigor, disease severity score, tiller count, yield, and fungal populations. Multifactor analyses of variance (ANOVA) were performed in R Studio (version 0.98.932, based on R i386 version 3.0.2). For all response variables except yield, data from the three locations were combined for simplicity. The use of the three locations was for testing repeatability of dynamics and not to define their broader applicability. Therefore, location was treated as a fixed variable for statistical purposes. The $\chi^{2}$ tests of homogeneity $(\alpha<0.05)$ were conducted to verify that there was no evidence of a violation of homogeneity of variance prior to combining trial data (Ramsey and Schafer 2002). Although they met the assumption of homogeneity of variance, yield was not combined between the three locations due to concerns that the variability in yields at Lutz Farm created by elk damage would mask yield effects across locations. This dynamic was not observed for other responses.

For variables deemed significant based on ANOVA, Fisher's protected least significant difference (LSD) $(\alpha<0.05)$ was used to compare treatment means. Population values were natural logtransformed after adding 1 to the values (because some of the populations had 0 values) prior to analysis. Other response variables were not transformed for analysis because their residuals graphs did not show a need for transformation. Regression analyses were conducted using ARC software (University of Minnesota) to analyze the relationship between pathogen populations. During regression analysis with ARC, response variables underwent normalizing transformations based on Box-Cox analyses.

The three greenhouse trials were analyzed separately, due to violation of the assumption of homogeneity of variance $\left(\chi^{2}\right.$ tests of homogeneity, $\alpha \leq 0.05)$. The three trials were first examined using regression analysis to determine the effect of pathogen population on the opposing pathogen populations. None of the trials exhibited evidence that population size had an effect on the opposing pathogen's populations, and the rest of the analyses were conducted using linear models to generate multifactor ANOVA in R Studio, as with the field data. As with field populations, greenhouse populations were natural log-transformed after adding 1 to the values prior to analysis and, when ANOVA results indicated significant differences, Fisher's protected LSD $(\alpha<0.05)$ was used to compare treatment responses.

\section{RESULTS}

Field location affects crop performance. Field location significantly affected yield, emergence, vigor, tiller count, disease severity (all $P<0.001)$, and $C$. sativus populations $(P=0.009)$ (Table 4). Location did not affect Fusarium population sizes $(P=$ $0.057)$. Block did not significantly affect any response variables at any of the locations (all $P>0.05$ ), with the sole exception being yield at Lutz Farm $(P=0.001)$, likely due to elk damage that differentially affected the blocks. There was no block effect for yield at Post Farm or Fort Ellis ( $P=0.08$ and 0.21 , respectively).

Pathogen inoculations decrease crop health. Yield varied significantly among the $C$. sativus treatments at two of the three field locations, based on multifactor ANOVA (Post Farm $P<0.001$ and Fort Ellis $P=0.04$ ) (Table 5). At the Post Farm, both isolates of C. sativus significantly reduced yield compared with plots not inoculated with C. sativus; at Fort Ellis, only isolate Cs2344 significantly reduced yield (Table 5). Yields at Lutz Farm did not vary significantly among $C$. sativus treatments $(P=0.51)$. Yield at the Post Farm also varied significantly among the $F$. pseudograminearum treatments $(P=$ $0.004)$, with all four isolates significantly reducing yield compared with the uninoculated control (Table 5). Yields at Fort Ellis and Lutz Farm did not vary significantly among $F$. pseudograminearum treatments $(P=0.54$ and 0.07 , respectively). Regression analysis did not identify a relationship between $C$. sativus populations and yield $\left(R^{2}=0.01, P=0.06\right)$ or between $F$. pseudograminearum populations and yield $\left(R^{2}=0.01, P=0.09\right)$.

TABLE 4. Means of all measured response variables at each location. Variables recorded were emergence (seedling count per $3 \mathrm{~m}$ row), vigor (0 to 5), tiller counts, disease severity score (DSS, 1 to 4), yield, and field populations of Fusarium spp. and C. sativus ${ }^{\mathrm{a}}$

\begin{tabular}{|c|c|c|c|c|c|c|c|}
\hline Location & Emergence & Vigor & Tiller counts & $\begin{array}{l}\text { Disease } \\
\text { severity }\end{array}$ & $\begin{array}{l}\text { Yield (metric } \\
\text { tons/ha) }\end{array}$ & $\begin{array}{l}\text { Fusarium copy } \\
\text { number }\end{array}$ & $\begin{array}{c}\text { Cochliobolus copy } \\
\text { number }\end{array}$ \\
\hline $\begin{array}{l}\text { Arthur H. Post Research } \\
\text { Farm }\end{array}$ & 60.9 & 3.86 & 85.6 & 1.49 & 4.54 & $9.38,92,806$ & $7.20,2,230$ \\
\hline Lutz Research Farm & 71.3 & 3.54 & 83.2 & 1.97 & 1.74 & $9.34,25,228$ & $6.20,2,496$ \\
\hline $\operatorname{LSD}(\alpha=0.05)^{\mathrm{b}}$ & 5.3 & 0.17 & 4.8 & 0.0028 & 0.14 & - & 0.59 \\
\hline$P$ value & $\begin{array}{l}F=7.74 \\
P<0.001\end{array}$ & $\begin{array}{c}F=19.04, \\
P<0.001\end{array}$ & $\begin{array}{c}F=40.42 \\
P<0.001\end{array}$ & $\begin{array}{l}F=26.81, \\
P<0.001\end{array}$ & $\begin{array}{c}F=101.85 \\
P<0.001\end{array}$ & $\begin{aligned} F & =2.91 \\
P & =0.057\end{aligned}$ & $\begin{array}{l}F=4.83 \\
P=0.009\end{array}$ \\
\hline
\end{tabular}

a Variables recorded were emergence (seedling count per $3 \mathrm{~m}$ row), vigor (0 to 5), tiller counts, disease severity score (DSS, 1 to 4 ), yield, and field populations of Fusarium spp. and C. sativus. Response variables all varied significantly between at least two of the field locations. Fusarium spp. and Cochliobolus sativus populations in crown tissue are represented by copy number measured by quantitative polymerase chain reaction, and have been natural $\log (\ln (\operatorname{copy}$ number +1$)$ ) transformed. Nontransformed means are italicized; $-=$ not applicable.

b Fisher's protected least significant difference. 
Across locations, emergence counts varied significantly among C. sativus treatments based on multifactor ANOVA $(P<0.001)$ (Table 5). Both C. sativus isolates significantly reduced emergence compared with plots not inoculated with $C$. sativus; isolate Cs2016 reduced emergence by $17.2 \%$, and Cs 2344 by $13.3 \%$. Emergence did not vary significantly among $F$. pseudograminearum treatments $(P=0.40)$. A significant interaction was observed between C. sativus isolate treatments and location $(P<0.001)$; patterns of emergence were similar across locations but emergence for the plots not inoculated with $C$. sativus was poor at the Post Farm, resulting in the significant interaction (data not shown).

Vigor at the combined locations varied significantly among C. sativus $(P<0.001)$ and $F$. pseudograminearum treatments $(P<$ 0.001 ), based on multifactor ANOVA (Table 5). Although both C. sativus isolates reduced vigor compared with plots not inoculated with $C$. sativus, isolate Cs2016 reduced vigor significantly more than isolate Cs2344 (Table 5). Additionally, a significant interaction effect was observed between $C$. sativus isolate and location $(P=$ 0.006), in which isolate Cs2016 reduced mean vigor more, compared with plots not inoculated with C. sativus, at the Post Farm location than at the other two locations based on Fisher's protected LSD ( $\alpha=0.05$, data not shown). Vigor varied significantly among the $F$. pseudograminearum treatments as well $(P<0.001)$; all four isolates significantly reduced vigor compared with the no-Fusarium treatment (Table 5). Isolates Fp2228 and Fp2317 reduced vigor significantly more than isolates Fp2234 and Fp2278 (Table 5). A significant interaction was observed between $F$. pseudograminearum treatment and location $(P<0.001)$; patterns of vigor were similar among the Fusarium treatments at the three locations but isolate Fp2228 reduced vigor more at Lutz Farm than it did at the other locations (data not shown).

None of the $C$. sativus treatments had a significant effect on disease severity score $(P=0.95)$. In contrast, disease severity score varied significantly among the $F$. pseudograminearum treatments $(P<0.001)$. Isolate Fp2228 significantly increased disease severity score to 1.80 in comparison with 1.45 in plots not inoculated with $F$. pseudograminearum; however, none of the other three $F$. pseudograminearum isolates significantly affected crown rot disease severity score (Table 5). Overall, Fusarium population sizes were significantly correlated with an increase in disease severity score $\left(R^{2}=0.14, P<0.001\right)$.

Competition observed in the field. There was significant variation among $C$. sativus treatments with regard to their effect on Fusarium populations $(P=0.03)$. Inoculation with isolate $C s 2344$ significantly reduced Fusarium populations compared with plots not inoculated with $C$. sativus (Table 6). Fusarium populations in plots inoculated with Cs2016 were intermediate in size and were not significantly different from plots not inoculated with C. sativus or those inoculated with Cs2344. Although pathogen inoculations had significant effects on reciprocal species, no correlation between populations of $C$. sativus and Fusarium spp. was detected $\left(R^{2}=\right.$ $0.01, P=0.07$ ).

Populations of $C$. sativus also varied significantly among the $F$. pseudograminearum treatments $(P=0.03)$. Inoculation with Fp2228 significantly reduced $C$. sativus populations compared with plots not inoculated with $F$. pseudograminearum (Table 6). Fisher's protected LSD $(\alpha<0.05)$ did not separate $C$. sativus populations inoculated with the remaining three isolates from plots with no F. pseudograminearum inoculation.

When plants were inoculated with $C$. sativus or with F. pseudograminearum, populations of that pathogen significantly increased (both $P<0.001$ ). In spite of high indigenous populations of C. sativus at the field locations, isolates Cs2344 and Cs2016 increased C. sativus populations 2.4 times and 1.5 times greater, respectively, than the populations in plots not inoculated with C. sativus (Table 6).

TABLE 6. Effect of inoculation with isolates of Fusarium pseudograminearum (F. pseudo) and Cochliobolus sativus on field populations of Fusarium spp. and $C$. sativus in McNeal spring wheat crowns, as represented by copy number measured by quantitative polymerase chain reaction ${ }^{\mathrm{a}}$

\begin{tabular}{lcc}
\hline Effect of isolates & $\begin{array}{c}\text { Fusarium copy } \\
\text { number }\end{array}$ & $\begin{array}{c}\text { Cochliobolus copy } \\
\text { number }\end{array}$ \\
\hline C. sativus & $F=3.40, P=0.03$ & $F=10.86, P<0.001$ \\
None & $\mathbf{1 0 . 0 5}, 102,493$ & $\mathbf{5 . 9 5}, 1,280$ \\
Cs2344 & $\mathbf{9 . 0 6 ,}, 81,939$ & $\mathbf{7 . 3 8}, 3,040$ \\
Cs2016 & $\mathbf{9 . 8 1}, 122,160$ & $\mathbf{6 . 8 2}, 1,872$ \\
LSD $(\alpha=0.05)$ & $\mathbf{0 . 7 7}$ & $\mathbf{0 . 5 9}$ \\
F. pseudo & F2.37, $P<0.001$ & $F=2.68, P=0.03$ \\
None & $\mathbf{5 . 9 9}, 7,392$ & $\mathbf{7 . 0 1}, 2,095$ \\
Fp2228 & $\mathbf{1 2 . 3 5 ,}, 299,187$ & $\mathbf{6 . 0 9}, 1,260$ \\
Fp2234 & $\mathbf{1 0 . 7 0}, 117,306$ & $\mathbf{7 . 3 0}, 2,922$ \\
Fp2317 & $\mathbf{1 0 . 1 2}, 53,938$ & $\mathbf{7 . 0 1}, 2,215$ \\
Fp2278 & $\mathbf{9 . 0 4}, 33,163$ & $\mathbf{6 . 6 7}, 1,829$ \\
LSD $(\alpha=0.05)$ & $\mathbf{1 . 0 0}$ & $\mathbf{0 . 7 7}$ \\
Untreated control & 13,813 & 2,427 \\
C. sativus - F. pseudo & $F=0.26, P=0.98$ & $F=0.49, P=0.86$ \\
isolate & & \\
\hline
\end{tabular}

a Data from the three field locations were combined. Fisher's protected least significant difference (LSD) values were calculated based on $\ln$ (copy number +1 ) transformations of data, and assigned to mean transformed values. Means of transformed values are shown in bold and nontransformed means are italicized.

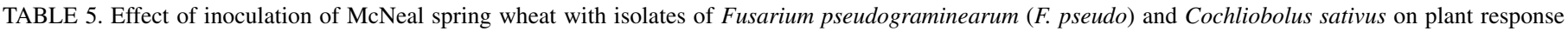

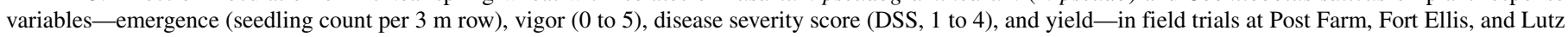
Farm $^{\mathrm{a}}$

\begin{tabular}{|c|c|c|c|c|c|c|}
\hline \multirow[b]{2}{*}{ Effect of isolates } & \multirow[b]{2}{*}{ Emergence } & \multirow[b]{2}{*}{ Vigor } & \multirow[b]{2}{*}{ DSS } & \multicolumn{3}{|c|}{ Yield (metric tons/ha) } \\
\hline & & & & Post & Ellis & Lutz \\
\hline C. sativus & $F=12.08, P<0.001$ & $F=89.86, P<0.001$ & $F=0.05, P=0.95$ & $F=15.15, P<0.001$ & $F=3.33, P=0.04$ & $F=0.68, P=0.51$ \\
\hline None & 73.4 & 4.5 & 1.55 & 4.92 & 1.92 & 1.75 \\
\hline $\mathrm{Cs} 2344$ & 63.6 & 3.6 & 1.55 & 4.47 & 1.74 & 1.80 \\
\hline Cs2016 & 60.8 & 3.4 & 1.54 & 4.21 & 1.70 & 1.68 \\
\hline $\operatorname{LSD}(\alpha=0.05)^{\mathrm{b}}$ & 5.3 & 0.17 & - & 0.27 & 0.19 & - \\
\hline F. pseudograminearum & $F=1.01, P=0.40$ & $F=9.80, P<0.001$ & $F=17.98, P<0.001$ & $F=4.76, P=0.003$ & $F=0.79, P=0.54$ & $F=2.31, P=0.07$ \\
\hline None & 64.4 & 4.2 & 1.45 & 4.87 & 1.78 & 1.70 \\
\hline Fp2228 & 66.3 & 3.6 & 1.80 & 4.18 & 1.82 & 1.71 \\
\hline Fp2234 & 69.6 & 3.9 & 1.51 & 4.58 & 1.67 & 1.80 \\
\hline Fp2317 & 63.0 & 3.5 & 1.49 & 4.40 & 1.87 & 1.55 \\
\hline Fp2278 & 66.5 & 3.9 & 1.46 & 4.64 & 1.80 & 1.95 \\
\hline $\operatorname{LSD}(\alpha=0.05)^{\mathrm{b}}$ & - & 0.23 & 0.097 & 0.34 & - & - \\
\hline Untreated control & 70.5 & 4.7 & 1.48 & 5.23 & 1.90 & 1.66 \\
\hline C. sativus-F. pseudo & $F=0.91, P=0.56$ & $F=0.77, P=0.72$ & $F=0.78, P=0.70$ & $F=0.69, P=0.70$ & $F=0.33, P=0.97$ & $F=1.34, P=0.25$ \\
\hline
\end{tabular}

a Emergence, vigor, and DSS were combined across locations. Yields for each location were analyzed separately due to substantial differences in means.

b Fisher's protected least significant difference. 
Isolates Fp2228, Fp2234, Fp2317, and Fp2278 significantly increased mean Fusarium populations 39, 15, 6.6, and 3.5 times, respectively, greater than plots not inoculated with F. pseudograminearum (Table 6).

Field dynamics confirmed in the greenhouse. Block had a significant effect on $C$. sativus populations in greenhouse trial 1 ( $F$ statistic $=5.024, P=0.0039)$, possibly due to insufficient plant size of the surrounding border rows that had been planted to reduce edge effects. No other significant block effects occurred in any of the trials (Fusarium spp. population trials 1, 2, and $3: P=0.21,0.52$, and 0.26 , respectively; $C$. sativus population trials 2 and $3: P=0.92$ and 0.075 , respectively).

Fusarium spp. populations varied significantly among $C$. sativus treatments in trials 1 and $3(P<0.001$ and $P=0.04$, respectively) (Table 7); Fusarium spp. populations in trial 2 did not vary among the treatments $(P=0.80)$. Isolate Cs2344 reduced Fusarium spp. populations in both trials 1 and 3 compared with pots not inoculated with $C$. sativus (Table 7). Isolate Cs 1033 significantly reduced Fusarium spp. populations in trial 1 as well but the effect was significantly less than that of isolate Cs2344. Isolate Cs2016 did not affect Fusarium spp. populations in any of the three trials (Table 7). A statistical interaction between individual $F$. pseudograminearum and $C$. sativus isolates was detected in greenhouse trial 1 (Table 7). In that trial, isolate-level interactions were observed (Table 8). Although isolates Cs1033 and Cs2344 were generally suppressive to all $F$. pseudograminearum isolates, based on Fisher's protected LSD, isolate Fp2228 was only significantly suppressed by isolate Cs2344. In addition, isolate Fp2234 was significantly suppressed by isolate Cs2016, an isolate that was otherwise nonsuppressive (Table 8). Although not significant (Table 7), a similar pattern was observed in trial 3 (data not shown).

Populations of $C$. sativus did not significantly vary among F. pseudograminearum treatments in any of the greenhouse trials $(P=$ 0.35 , trial $1 ; P=0.47$, trial 2 ; and $P=0.36$, trial 3). A single, significant isolate-isolate interaction $(P=0.01)$ was identified that involved Fusarium isolate Fp2228 suppressing Cochliobolus isolate Cs1033 in trial 2 (Fisher's protected LSD, $\alpha<0.05$ ); C. sativus populations in Cs1033 pots inoculated with Fp2228 were 83.5\% lower than populations in Cs1033 pots not inoculated with $F$. pseudograminearum.

In two of the three greenhouse trials, $C$. sativus populations varied significantly among the $C$. sativus treatments, based on multifactor ANOVA $(P=0.14$, trial $1 ; P<0.001$, trial 2 ; and $P=0.009$, trial 3$)$. The increase was largely due to the increased populations observed in pots inoculated with Cs2344, based on Fisher's protected LSD $(\alpha<0.05$, data not shown). Fusarium populations varied significantly among the $F$. pseudograminearum treatments in all three trials (Table 7). Of the F. pseudograminearum isolates, Fp2228 and
Fp2317 increased Fusarium spp. populations the most in all three trials; isolate Fp2234 significantly increased Fusarium spp. populations in two of the three trials (trials 1 and 3), and Fp2278 increased Fusarium spp. populations in an individual trial (trial 1, Fisher's protected LSD, $\alpha<0.05)$.

Regression analysis of fungal population sizes in ARC provided no evidence that the fungal populations of the two pathogens significantly correlated $\left(R^{2}=0.01, P=0.36\right.$, trial $1 ; R^{2}=0.01, P=$ 0.80 , trial 2; and $R^{2}=0.02, P=0.20$, trial 3).

\section{DISCUSSION}

The observed suppression of $F$. pseudograminearum by C. sativus in these trials represents the first report of this behavior between these pathogens. The reciprocal suppression that is documented between species in this report raises the level of interaction between these two pathogens from an asymmetric suppression of $C$. sativus by $F$. pseudograminearum, as previously reported (Fernandez and Jefferson 2004; Moya-Elizondo et al. 2011a; Tinline 1977), to one of interspecific competition. The patterns of suppression among isolates of both species for this study were consistent across field and greenhouse trials; that is to say, isolates Cs2344 and Fp2228 were consistently the most suppressive isolates, and Cs2016 and Fp2234 were consistently the least suppressive isolates. This leads us to believe that the competitive interactions described here more accurately describe the dynamics between these pathogens than previous reports. Given the technical limitations in quantification of pathogen populations (Fernandez and Jefferson 2004; Tinline 1977), the inability in some studies to establish $C$. sativus populations above background levels (Moya-Elizondo et al. 2011a), and the high variability observed in

TABLE 8. Effect of interactions between isolates of Fusarium pseudograminearum (F. pseudo) and C. sativus on Fusarium spp. populations in greenhouse trial $1(F=2.07, P=0.03)^{\mathrm{a}}$

\begin{tabular}{lclll}
\hline Isolate & No C. sativus & \multicolumn{1}{c}{ Cs1033 } & \multicolumn{1}{c}{ Cs2016 } & Cs2344 \\
\hline No F. pseudo & $\mathbf{0 . 0 0 ,} 0$ & $\mathbf{2 . 1 6}, 1,405$ & $\mathbf{3 . 8 5}, 846$ & $\mathbf{0 . 0 0 ,} 0$ \\
Fp2228 & $\mathbf{1 1 . 1 6 ,} 92,057$ & $\mathbf{8 . 2 8 ,}, 35,167$ & $\mathbf{9 . 1 2}, 14,840$ & $\mathbf{2 . 9 2 ,}, 128$ \\
Fp2234 & $\mathbf{6 . 9 2}, 9,137$ & $\mathbf{3 . 4 2}, 81$ & $\mathbf{0 . 8 3}, 7$ & $\mathbf{3 . 8 0}, 657$ \\
Fp2278 & $\mathbf{5 . 5 0}, 33,422$ & $\mathbf{4 . 0 3}, 586$ & $\mathbf{6 . 0 9}, 24,837$ & $\mathbf{0 . 9 5}, 5$ \\
Fp2317 & $\mathbf{1 0 . 0 0 ,} 43,680$ & $\mathbf{4 . 0 0 ,} 56$ & $\mathbf{8 . 3 6}, 68,064$ & $\mathbf{3 . 8 5}, 47$ \\
LSD $(\alpha=0.05)$ & $\mathbf{4 . 0 4}$ & $\mathbf{4 . 0 4}$ & $\mathbf{4 . 0 4}$ & $\mathbf{4 . 0 4}$
\end{tabular}

a Fisher's protected least significant difference (LSD) values were calculated based on $\ln ($ copy number +1 ) transformations of data, and assigned to mean transformed values. Means of transformed values are shown in bold and nontransformed means are italicized.

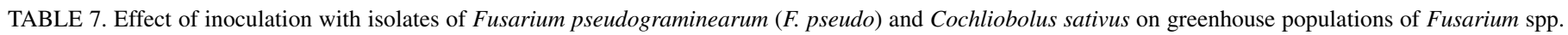
in $\mathrm{McNeal}$ spring wheat crowns, as represented by copy number measured by quantitative polymerase chain reaction

\begin{tabular}{|c|c|c|c|}
\hline \multirow[b]{2}{*}{ Effect of isolates } & \multicolumn{3}{|c|}{ Fusarium copy number ${ }^{\mathrm{a}}$} \\
\hline & Trial 1 & Trial 2 & Trial 3 \\
\hline C. sativus & $F=8.00, P<0.001$ & $F=0.34, P=0.80$ & $F=2.80, P=0.04$ \\
\hline None & $\mathbf{6 . 7 2}, 33,213$ & $\mathbf{2 . 9 1}, 1,472$ & $\mathbf{5 . 2 6}, 40,523$ \\
\hline Cs2344 & $\mathbf{2 . 3 0}, 167$ & $2.57,126$ & $1.44,40$ \\
\hline Cs2016 & $\mathbf{5 . 6 5}, 21,719$ & 2.56, 75 & $\mathbf{4 . 5 4}, 76,430$ \\
\hline Cs1033 & 4.38, 7,459 & 3.39, 4,331 & $\mathbf{3 . 3 1}, 69,760$ \\
\hline $\operatorname{LSD}(\alpha=0.05)$ & 1.81 & - & 2.31 \\
\hline F. pseudograminearum & $F=11.75, P<0.001$ & $F=5.19, P=0.001$ & $F=9.16, P<0.001$ \\
\hline None & 1.60, 643 & $\mathbf{0 . 3 1}, 4$ & $\mathbf{0 . 1 8}, 1$ \\
\hline Fp2228 & $\mathbf{8 . 2 0}, 37,909$ & 5.11, 2,808 & $\mathbf{5 . 1 3}, 127,568$ \\
\hline Fp2234 & 3.74, 2,591 & 2.47, 277 & $4.75,4,731$ \\
\hline Fp2317 & $\mathbf{6 . 7 3}, 30,316$ & $\mathbf{3 . 8 1}, 2,168$ & $\mathbf{6 . 4 6}, 199,764$ \\
\hline Fp2278 & $\mathbf{4 . 3 5}, 11,939$ & $\mathbf{2 . 5 0}, 2,248$ & 1.67, 7,510 \\
\hline $\operatorname{LSD}(\alpha=0.05)$ & 2.09 & 2.24 & 2.58 \\
\hline Untreated control & 0 & 0 & 4 \\
\hline C. sativus-F. pseudo isolate & $F=2.07, P=0.03$ & $F=1.22, P=0.30$ & $F=1.88, P=0.055$ \\
\hline
\end{tabular}

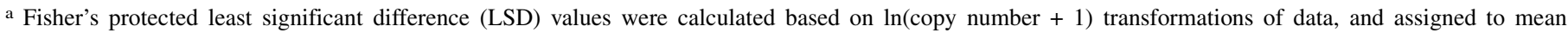
transformed values. Means of transformed values are shown in bold and nontransformed means are italicized. 
suppressiveness among $C$. sativus isolates for this study, it becomes apparent why competitive dynamics were not observed before. Competition provides an unexplored mechanism for explaining negative correlations previously reported between populations of these two pathogens in field surveys (Fernandez and Jefferson 2004; Moya-Elizondo et al. 2011b). This report may also be unique in being the first report of competition between fungal plant pathogens as observed in the field. Several previous reports of competition have been made that were limited to greenhouse or in vitro studies (Adee et al. 1990; Al-Naimi et al. 2005; da Luz and Bergstrom 1987) but no fieldbased reports of pathogen competition have been recorded.

Interspecific competition between $F$. pseudograminearum and C. sativus bears important practical and ecological implications (Tollenaere et al. 2016). Foremost, it formalizes suspicions that reciprocal pathogen replacement occurs between these two organisms. Although the symmetry of these interactions needs further exploration, the competitive nature of their interaction indicates that, at some level, both of these pathogens will need to be controlled in order to fully realize yield benefits of controlling either pathogen alone. This is supported by previous studies that have observed less overall disease in coinoculated plots for these two pathogens as compared with plots inoculated with either pathogen alone (Scardaci and Webster 1981). The corollary of pathogen replacement is that competitive interactions among pathogens implies a more complex host selection and fitness process; in essence, the benefits of developing resistance to one pathogen by the plant host is diffused as the unsuccessful pathogen is replaced by its competitor (May and Nelson 2014; Méthot and Alizon 2014). The level of diffusion of selection pressure would reflect both the degree of mutual disease suppression achieved between species and the frequency of their interactions. This is currently unknown because endemic populations for both pathogens confound responses in the field, leaving just a glimpse of the dynamics that may be at play. Diffusion of selection pressure may partially explain the apparent lack of specific resistance in wheat germplasm for $C$. sativus and $F$. pseudograminearum (Burgess et al. 2001; Cook et al. 1990). These two pathogens are hardly alone on this score, because specific resistance to many root pathogens is rare.

Suppression was not linked to population sizes for either species, nor did their interactions display zero-sum dynamics. Although suppression was associated with relative aggressiveness among F. pseudograminearum isolates, it was not associated with relative aggressiveness displayed among C. sativus isolates tested in followup trials (data not shown). This argues for competitive mechanisms associated only weakly with population sizes such as interference or host-elicited defense responses, and not associated with mechanisms tightly linked to pathogen populations such as resource depletion, physical exclusion, or hyperparasitism. Bolstering this claim, antibiosis was observed in vitro through the generation of inhibition zones by suppressive $C$. sativus isolates but not by the nonsuppressive isolate Cs2016. The rapid growth of the Fusarium isolates in culture prevented reciprocal examination for Fusarium spp., and Fusarium suppressiveness was not associated with relative DON production (Table 1, DON values). However, previous studies of a closely related species, $F$. culmorum, have reported in vitro suppression of conidial germination for $C$. sativus via unknown mechanisms (Ledingham 1942), and preemptive inoculation with F. culmorum or F. graminearum prevented later infections by $C$. sativus (Scardaci and Webster 1981; Tinline 1977). Given these observations, interference through antibiosis appears to be a likely mechanism of competition. Both species are noted toxin producers. Although enhanced virulence may explain the presence of toxic phenotypes within populations of both pathogen species, it does not explain the persistence of the phenotype when occurring within insensitive host populations (Scheffer 1989). Perhaps conferred competitive advantages within microbial communities would explain the persistence of toxin production within pathogen communities in the absence of a virulence benefit.
The variability observed in these trials among isolates of each species should provide valuable tools for determining whether antibiosis or some other competitive mechanism is involved. Although genetic crosses are not possible among individuals of F. pseudograminearum, crosses among suppressive and nonsuppressive $C$. sativus isolates may be performed, and these should readily identify the genetic control of suppressiveness. With advances in metabolomics and genomics, associations between suppressiveness and metabolic products or expressed genes may be easily assessed. Similar trials may be conducted to identify genes associated with insensitive phenotypes of each species as well. Without the ability to perform crosses, identifying mechanism of suppressiveness for F. pseudograminearum will require the characterization of additional individuals to provide sufficient resolution for identifying mechanisms. Alternatively, individuals of the closely related $F$. graminearum may be found with similar effects that may be used in its stead for production of crosses with segregating phenotypes.

In summary, this is the first report to confirm in-field competition between two fungal plant pathogens, and also the first report of $C$. sativus suppressing $F$. pseudograminearum. These findings reveal a more extensive interaction between these pathogens species than was previously known. This work also identifies variability among individuals of both species to suppress and to be suppressed. From a practical viewpoint, this variability provides tools for exploring the mechanisms of competition and perhaps identifying specific processes involved. Numerous models have been proposed for explaining competitive interactions among pathogens and how they affect evolution of virulence and host resistance (Lion 2013; Nowak and May 1994). The trials described here provide new tools for advancing our understanding of pathogen ecology and evolutionary processes that occur in a complex pathogen community.

\section{ACKNOWLEDGMENTS}

This research was supported by funds from the Montana Wheat and Barley Committee. We thank the Montana Foundation Seed Program, who provided seed for this project, and the United States Department of Agriculture Institute of Food and Agriculture, Hatch Project number 1002597.

\section{LITERATURE CITED}

Adee, S. R., Pfender, W. F., and Hartnett, D. C. 1990. Competition between Pyrenophora tritici-repentis and Septoria nodorum in the wheat leaf as measured with de Wit replacement series. Phytopathology 80:1177-1182.

Al-Naimi, F. A., Garrett, K. A., and Bockus, W. W. 2005. Competition, facilitation, and niche differentiation in two foliar pathogens. Oecologia 143:449-457.

Bockus, W. W., and Shroyer, J. P. 1998. The impact of reduced tillage on soilborne plant pathogens. Annu. Rev. Phytopathol. 36:485-500.

Boddy, L. 2000. Interspecific combative interactions between wood-decaying basidiomycetes. FEMS Microbiol. Ecol. 31:185-194.

Bruehl, G. W. 1987. Soilborne Plant Pathogens. Macmillan Publishing Company, New York.

Burgess, L. W., Backhouse, D., Summerell, B. A., and Swan, L. J. 2001. Crown rot of wheat. Pages 271-294 in: Fusarium: Paul E. Nelson Memorial Symp. American Phytopathological Society, St. Paul, MN.

Burgess, L. W., Dodman, R. L., Pont, W., and Mayers, P. 1981. Fusarium Diseases of Wheat, Maize, and Grain Sorghum in Eastern Australia. The Pennsylvania State University Press, University Park, PA.

Cassini, R. 1981. Fusarium diseases of wheat and corn in western Europe. Pages 56-63 in: Fusarium: Diseases, Biology and Taxonomy. P. E. Nelson, T. A. Toussoun, and R. J. Cook, eds. Pennsylvania State University Press, University Park.

Cline, W. R. 2007. Global Warming and Agriculture: Impact Estimates by Country. Center for Global Development and the Peterson Institute for International Economics, Washington, DC.

Conner, R. L., Lindwall, C. W., and Atkinson, T. G. 1987. Influence of minimum tillage on severity of common root rot in wheat. Can. J. Plant Pathol. 9:56-58.

Cook, R. J. 1981. Fusarium diseases of wheat and other small grains in North America. Pages 39-52 in: Fusarium: Diseases, Biology and Taxonomy. P. E. Nelson, T. A. Toussoun, and R. J. Cook, eds. Pennsylvania State University Press, University Park. 
Cook, R. J. 2010. Fusarium root, crown, and foot rots and associated seedling diseases. Pages 37-39 in: Compendium of Wheat Diseases and Pests, third ed. W. W. Bockus, R. L. Bowden, R. M. Hunger, W. L. Morrill, T. D. Murray, and R. W. Smiley, eds. American Phytopathological Society Press, St. Paul, MN.

Cook, R. J., Chamswarng, C., and Tang, W. H. 1990. Influence of wheat chaff and tillage on Pythium populations in soil and Pythium damage to wheat. Soil Biol. Biochem. 22:939-947.

da Luz, W. C., and Bergstrom, G. C. 1987. Interactions between Cochliobolus sativus and Pyrenophora tritici-repentis on wheat leaves. Phytopathology 77:1355-1360.

Dodman, R. L., and Wildermuth, G. B. 1987. Inoculation methods for assessing resistance in wheat to crown rot caused by Fusarium graminearum group 1. Aust. J. Agric. Res. 38:473-486.

Dyer, A. T., Johnston, R. H., Hogg, A. C., and Johnston, J. A. 2009. Comparison of pathogenicity of the Fusarium crown rot (FCR) complex (F. culmorum, F. pseudograminearum and $F$. graminearum) on hard red spring and durum wheat. Eur. J. Plant Pathol. 125:387-395.

El Hadrami, A., Wally, O., Adam, L. R., and Daayf, F. 2007. PCR-based determination of colonization patterns during potato tuber infection by single and multiple pathogens. Eur. J. Plant Pathol. 117:201-218.

Fernandez, M. R., and Jefferson, P. G. 2004. Fungal populations in roots and crowns of common and durum wheat in Saskatchewan. Can. J. Plant Pathol. 26:325-334.

Gibbs, J. N., and Smith, M. E. 1978. Antagonism during the saprophytic phase of the life cycle of two pathogens of woody hosts-Heterobasidion annosum and Ceratocystis ulmi. Ann. Appl. Biol. 89:125-128.

Hogg, A. C., Johnston, R. H., and Dyer, A. T. 2007. Applying real-time quantitative PCR to Fusarium crown rot of wheat. Plant Dis. 91:1021-1028.

Hogg, A. C., Johnston, R. H., Johnston, J. A., Klouser, L., Kephart, K. D., and Dyer, A. T. 2010. Monitoring Fusarium crown rot populations in spring wheat residues using quantitative real-time polymerase chain reaction. Phytopathology 100:49-57.

Knight, N., and Sutherland, M. 2015. Culm discolouration as an indicator of Fusarium pseudograminearum biomass. Australas. Plant Pathol. 44:319-326.

Knight, N. L., Sutherland, M. W., Martin, A., and Herde, D. J. 2012. Assessment of Infection by Fusarium pseudograminearum in wheat seedling tissues using quantitative PCR and a visual discoloration scale. Plant Dis. 96:1661-1669.

Ledingham, R. J. 1942. Observation on antagonism in inoculation tests of wheat with Helminthosporium sativus P.K. \& B., and Fusarium culmorum (W.G.SM.) Sacc. Sci. Agric. 22:688-697.

Ledingham, R. J., Atkinson, T. G., Horricks, J. S., Mills, J. T., Piening, L., and Tinline, R. D. 1973. Wheat losses due to common root rot in the prairie provinces of Canada. Can. J. Plant Dis. Surv. 53:113-122.

Le May, C., Potage, G., Andrivon, D., Tivoli, B., and Outreman, Y. 2009. Plant disease complex: Antagonism and synergism between pathogens of the Ascochyta blight complex on pea. J. Phytopathol. 157:715-721.

Lion, S. 2013. Multiple infections, kin selection and the evolutionary epidemiology of parasite traits. J. Evol. Biol. 26:2107-2122.

Lutz, M. P., Feichtinger, G., Défago, G., and Duffy, B. 2003. Mycotoxigenic Fusarium and deoxynivalenol production repress chitinase gene expression in the biocontrol agent Trichoderma atroviride P1. Appl. Environ. Microbiol. 69:3077-3084

Mathre, D. E., and Johnston, R. H. 1975. Cephalosporium stripe of winter wheat: Procedures for determining host response. Crop Sci. 15:591-594.

Mathre, D. E., Johnston, R. H., and Grey, W. E. 2003. Diagnosis of common root rot of wheat and barley. Online publication. Plant Health Prog. doi.org/ 10.1094/PHP-2003-0819-01-DG

May, G., and Nelson, P. 2014. Defensive mutualisms: Do microbial interactions within hosts drive the evolution of defensive traits? Funct. Ecol. 28:356-363.

Méthot, P.-O., and Alizon, S. 2014. What is a pathogen? Toward a process view of host-parasite interactions. Virulence 5:775-785.

Moya-Elizondo, E. A., Jacobsen, B. J., Hogg, A. C., and Dyer, A. T. 2011a. Population dynamics between Fusarium pseudograminearum and Bipolaris sorokiniana in wheat stems using real-time qPCR. Plant Dis. 95:1089-1098.
Moya-Elizondo, E. A., Rew, L. J., Jacobsen, B. J., Hogg, A. C., and Dyer, A. T. 2011 b. Distribution and prevalence of Fusarium crown rot and common root rot pathogens of wheat in Montana. Plant Dis. 95:1099-1108.

Mudge, A. M., Dill-Macky, R., Dong, Y., Gardiner, D. M., White, R. G., and Manners, J. M. 2006. A role for the mycotoxin deoxynivalenol in stem colonisation during crown rot disease of wheat caused by Fusarium graminearum and Fusarium pseudograminearum. Physiol. Mol. Plant Pathol. 69:73-85.

Nolan, S., Cooke, B. M., and Monahan, F. J. 1999. Studies on the interaction between Septoria tritici and Stagonospora nodorum in wheat. Eur. J. Plant Pathol. 105:917-925.

Nowak, M. A., and May, R. M. 1994. Superinfection and the evolution of parasite virulence. Proc. R. Soc. Lond. B Biol. Sci. 255:81-89.

Pereyra, S. A., Dill-Macky, R., and Sims, A. L. 2004. Survival and inoculum production of Gibberella zeae in wheat residue. Plant Dis. 88:724-730.

Ramsey, F. L., and Schafer, D. W. 2002. The Statistical Sleuth: A Course in Methods of Data Analysis, 2nd ed. Thompson Learning, Inc., Pacific Grove, CA.

Round, P. A., and Wheeler, B. E. J. 1978. Interactions of Puccinia hordei and Erysiphe graminis on seedling barley. Ann. Appl. Biol. 89:21-35.

Scardaci, S. C., and Webster, R. K. 1981. Antagonism between the cereal root rot pathogens Fusarium graminearum and Bipolaris sorokiniana. Plant Dis. 65:965-967.

Scheffer, R. P. 1989. Ecological consequences of toxin production by Cochliobolus and related fungi. Pages 285-300 in: Phytotoxins and Plant Pathogenesis. Springer, Berlin, Germany.

Scherm, B., Balmas, V., Spanu, F., Pani, G., Delogu, G., Pasquali, M., and Migheli, Q. 2013. Fusarium culmorum: Causal agent of foot and root rot and head blight on wheat. Mol. Plant Pathol. 14:323-341.

Smiley, R. W., Gourlie, J. A., Easley, S. A., Patterson, L.-M., and Whittaker, R. G. 2005. Crop damage estimates for crown rot of wheat and barley in the Pacific Northwest. Plant Dis. 89:595-604.

Smiley, R. W., and Patterson, L.-M. 1996. Pathogenic fungi associated with Fusarium foot rot of winter wheat in the semiarid Pacific Northwest. Plant Dis. 80:944-949.

Stephens, A. E. A., Srivastava, S., and Myers, J. H. 2013. Strength in numbers? Effects of multiple natural enemy species on plant performance. Proc. R. Soc. B. 280:20122756.

Tinline, R. D. 1977. Multiple infections of subcrown internodes of wheat (Triticum aestivum) by common root rot fungi. Can. J. Bot. 55:30-34.

Tinline, R. D., and Spurr, D. T. 1991. Agronomic practices and common root rot in spring wheat: Effect of tillage on disease and inoculum density of Cochliobolus sativus in soil. Can. J. Plant Pathol. 13:258-266.

Tollenaere, C., Susi, H., and Laine, A.-L. 2016. Evolutionary and epidemiological implications of multiple infection in plants. Trends Plant Sci. 21: 80-90.

Weller, D. M., Cook, R. J., MacNish, G., Bassett, E. N., Powelson, R. L., and Petersen, R. R. 1986. Rhizoctonia root rot of small grains favored by reduced tillage in the Pacific Northwest. Plant Dis. 70:70-73.

Wiese, M. V. 1987. Common (dry land) root and foot rot and associated leaf and seedling diseases. Pages 53-55 in: Compendium of Wheat Diseases, second ed. American Phytopathological Society, St. Paul, MN.

Wildermuth, G. B., McNamara, R. B., and Quick, J. S. 2001. Crown depth and susceptibility to crown rot in wheat. Euphytica 122:397-405.

Wildermuth, G. B., Thomas, G. A., Radford, B. J., McNamara, R. B., and Kelly, A. 1997. Crown rot and common root rot in wheat grown under different tillage and stubble treatments in southern Queensland, Australia. Soil Tillage Res. 44:211-224.

Windels, C. E., and Wiersma, J. V. 1992. Incidence of Bipolaris and Fusarium on subcrown internodes of spring barley and wheat grown in continuous conservation tillage. Phytopathology 82:699-705.

Yang, L., Xie, J., Jiang, D., Fu, Y., Li, G., and Lin, F. 2008. Antifungal substances produced by Penicillium oxalicum strain PY-1-Potential antibiotics against plant pathogenic fungi. World J. Microbiol. Biotechnol. 24:909-915. 